\title{
Phospholipid metabolism in the cochlea: Differences between base and apex
}

\author{
Andrew S. Niedzielski and Jochen Schacht \\ Kresge Hearing Research Institute, University of Michigan, Ann Arbor, Michigan, U.S.A.
}

(Received 23 May 1991; accepted 20 July 1991)

\begin{abstract}
Phospholipid-derived second messenger systems are one of the primary means for the transduction of extracellular signals to intracellular effector sites. We have investigated the longitudinal distribution of phospholipid metabolism in the guinea pig cochlea because of increasing evidence that the apex and base process auditory signals differently. Phospholipid metabolism was assayed by measuring the incorporation of radioactive phosphate $\left({ }^{32} \mathrm{P}_{\mathrm{i}}\right)$ into lipids of the organ of Corti and the lateral wall tissues (stria vascularis and spiral ligament). ${ }^{32} \mathrm{P}-\mathrm{labeling}$ of total phospholipids was higher in the apex than the base, and individual phospholipids exhibited a tissue-specific base/apex distribution. Phosphatidylinositol was the most abundant of the labeled lipids in all tissues except the basal lateral wall, where phosphatidylinositol and phosphatidylcholine were labeled to a similar extent. Experiments on the availability of $\left[{ }^{32} \mathrm{P}\right]$-ATP and other non-lipid substrates (inositol, choline, and cytidine) suggested that the base/apex distribution of phospholipid metabolism is based on differences in enzymatic activities. Additional evidence for this is an increased hydrolysis of phosphoinositides in the apex. The base/apex distribution of lipid metabolism suggests that physiological and pathological mechanisms involving phospholipids differ between the turns of the cochlea.
\end{abstract}

Cochlea; Organ of Corti; Stria vascularis; Phosphatidylcholine; Phosphatidylinositol; Second messengers

\section{Introduction}

Second messenger systems are the primary means by which cells process external signals that control and regulate their physiology and metabolism. Both the adenylate cyclase (Ahlström et al., 1975; Schacht, 1985) and the phosphoinositide second messenger systems (Orsulakova et al., 1976; Schacht and Zenner, 1987; Guiramand et al., 1990) are known to exist in the inner ear. In the latter, which constitutes the major phospholipid-based second messenger system, the binding of extracellular signals to specific membrane receptors stimulates the hydrolysis of phosphatidylinositol 4,5-bisphosphate to inositol 1,4,5-trisphosphate $\left(\mathrm{InsP}_{3}\right)$ and diacylglycerol (DG). Ins $\mathrm{P}_{3}$ in turn releases intracellular $\mathrm{Ca}^{2+}$, whereas $\mathrm{DG}$ activates protein kinase $\mathrm{C}$. These two events ultimately result in the physiological response of the cell to the external stimulus. Other lipid-based messenger systems may operate through the hydrolysis of phosphatidylcholine (Pelech and Vance, 1989), glycosyl phosphatidylinositol (Lisanti et al., 1990), or the release of arachidonic acid (Axelrod et al., 1988).

Correspondence to: Jochen Schacht, Kresge Hearing Research Institute, University of Michigan, 1301 East Ann Street, Ann Arbor, MI 48109-0506, U.S.A. Fax: (313) 764-0014.
While the importance of second messenger systems has long been established, little is known about their function in the inner ear. We have previously implicated cochlear phospholipid metabolism in the action of insulin (Wang and Schacht, 1990), the processing of acoustic stimulation (Ono and Schacht, 1989), and the motility of outer hair cells (Schacht and Zenner, 1987) and have also examined muscarinic receptor-mediated release of inositol phosphates in the organ of Corti (Niedzielski and Schacht, 1991).

Anatomical, biochemical, and electrophysiological evidence suggest that processing of auditory signals may differ between the base and apex of the cochlea. For example, GABAergic efferent neurons are found exclusively in the apex of the cochlea (Eybalin et al., 1988; Fex et al., 1986) while cholinergic efferent innervation of the outer hair cells decreases from base to apex (Spoendlin, 1985). The latter parallels the base/apex distribution of acetylcholinesterase and choline acetyltransferase (Godfrey and Ross, 1985). In the stria vascularis, $\mathrm{Na}^{+} \cdot \mathrm{K}^{+}$ATPase is generally considered to be responsible for the maintenance of the unique ion balance of the endolymph (Offner et al., 1987). The increased concentration of endolymphatic $\mathrm{K}^{+}$in the base (Sterkers, 1985) parallels the distribution of strial $\mathrm{Na}^{+}-\mathrm{K}^{+}$ATPase (Kuijpers and Bonting, 1969). 
In this study, we attempt to discern the role of the inositol second messenger cascade in the cochlea by determining the base/apex distribution of phospholipid metabolism. The association of base/apex differences in phosphoinositide metabolism with other known cochlear gradients could suggest processes that are regulated by the inositol lipid cascade.

\section{Methods}

\section{Tissue preparation}

The otic capsules of adult pigmented guinea pigs $(250-350 \mathrm{~g})$ were removed and placed in incubation buffer at room temperature $(142 \mathrm{mM} \mathrm{NaCl}, 1 \mathrm{mM}$ $\mathrm{MgCl}_{2}, 5.6 \mathrm{mM} \mathrm{KCl}, 2.2 \mathrm{mM} \mathrm{CaCl}_{2}, 3.6 \mathrm{mM} \mathrm{NaHCO}_{3}$, $5.6 \mathrm{mM}$ glucose, $30 \mathrm{mM}$ sodium HEPES, pH 7.4). The combined lateral wall tissues (stria vascularis and spiral ligament) and the organ of Corti were dissected separately from the cochleae and placed in $50 \mu \mathrm{l}$ of incubation buffer. Apical tissues were defined as those in turns 3 and 4; basal tissue was taken from turns 1 and 2 of the organ of Corti or turn 1 of the lateral wall.

\section{Phospholipid labeling}

Phospholipid labeling was initiated by the addition of $\left[{ }^{32} \mathrm{P}\right]$-orthophosphate (ICN Radiochemicals, Irvine, $\mathrm{CA}$; approximately $80 \mu \mathrm{Ci}{ }^{32} \mathrm{P}_{i}$ in $50 \mu \mathrm{l}$ of incubation buffer) to the tissue, which was then incubated at $37^{\circ}$ for up to $90 \mathrm{~min}$. Labeling was terminated by the addition of chloroform/methanol $(1: 2)$ and phospholipids were extracted (Schacht, 1976) and scparatcd on thin-layer chromatographic plates (Van Rooijen et al., 1983). Radioactive lipids were located from an autoradiograph of the plate, scraped into vials and quantified by liquid scintillation counting. Alternatively, the radioactivity on the TLC plate was analyzed using a Vanguard TLC scanner (Radiomatic Instruments, Tampa, FL). Protein content of tissue samples was determined by the method of Bradford (1976).

\section{Glucose-6-phosphate labeling}

In a double-label procedure, ${ }^{32} \mathrm{P}_{\mathrm{i}}(0.1 \mathrm{mCi} / \mathrm{ml})$ was incubated with the tissue in $90 \mu \mathrm{l}$ of incubation buffer at $37^{\circ} \mathrm{C}$ for $75 \mathrm{~min}$. Then, $2-\left[1,2-{ }^{3} \mathrm{H}\right]$ deoxy-D-glucose (40 Ci/mmol; American Radiolabeled Chemicals Inc., St. Louis, MO) was added to a final concentration of $250 \mathrm{nM}$ and the incubation continued for an additional $15 \mathrm{~min}$. The incubation was terminated with $65 \mu \mathrm{l}$ of acetone and then placed on ice. After centrifugation, $120 \mu \mathrm{l}$ aliquots were removed for paper chromatographic separation of glucose and deoxyglucose 6-phosphates (Bandurski and Axelrod, 1951).

\section{Phosphoinositide hydrolysis}

In order to label the inositol lipid pool, isolated organ of Corti was incubated for $2 \mathrm{~h}$ at $37^{\circ} \mathrm{C}$ in $50 \mu \mathrm{l}$ of Hanks' balanced salt solution [HBSS (pH 7.4), buffered with $5 \mathrm{mM}$ sodium HEPES; adjusted to 300 mOsm] with $1 \mathrm{mM}$ cytidine and $20 \mu \mathrm{Ci}$ myo-[2- $\left.{ }^{3} \mathrm{H}\right]$ inositol (Amersham Corp., Arlington Heights, IL). After removing the $\left[{ }^{3} \mathrm{H}\right]$ inositol-containing buffer and washing twice with $0.5 \mathrm{ml}$ HBSS, $90 \mathrm{ml}$ of HBSS containing $10 \mathrm{mM} \mathrm{LiCl}$ were added. $\mathrm{LiCl}$ inhibits the hydrolysis of inositol phosphates (IPs) that are released from the prelabeled phosphoinositides (Hallcher and Sherman, 1980). Following forty min of incubation at $37^{\circ}$, phosphoinositide hydrolysis was terminated by the addition of chloroform/methanol (1:2). After partitioning of aqueous and chloroform phases, the inositol phosphates were separated from inositol on Dowex formate columns (Dean and Beaven, 1989).

\section{Results}

\section{Time course}

The time course of phospholipid labeling was determined in apical and basal sections of both the combined lateral wall tissues (stria vascularis and spiral ligament) and the organ of Corti (Fig. 1). All tissues exhibited a lag phase in ${ }^{32}$ P-incorporation during the first $60 \mathrm{~min}$ of incubation and the rate of labeling increased considerably between 60 and $90 \mathrm{~min}$. Ninety min was taken as the standard period of incubation for subsequent experiments due to the clear differences between apical and basal phospholipid labeling.

After $90 \mathrm{~min}$ of incubation, incorporation of ${ }^{32} \mathrm{P}_{\mathrm{i}}$ per microgram protein was highest for phospholipids in the

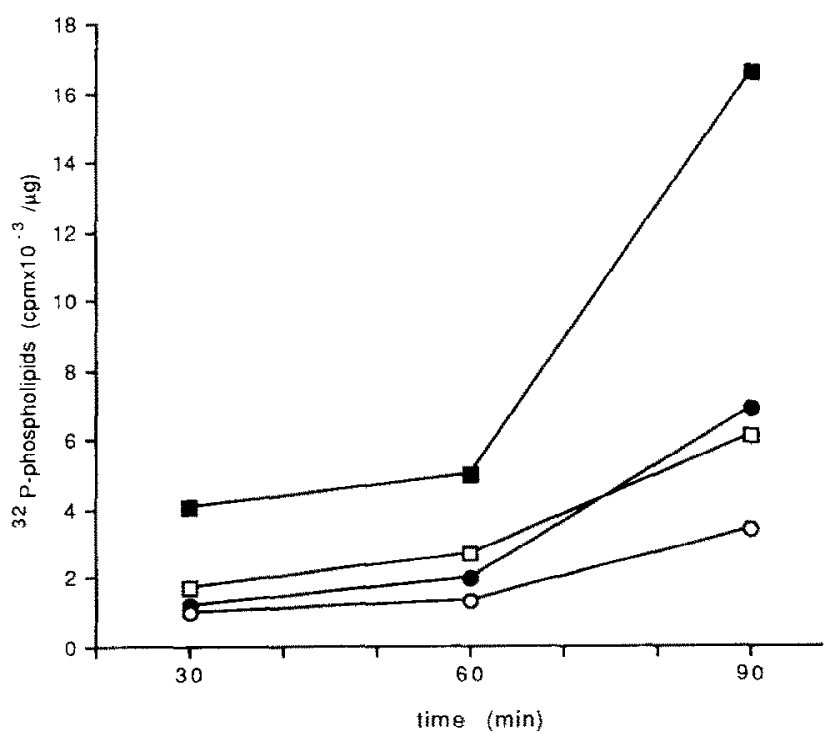

Fig. 1. Time course of labelling of cochlear phospholipids. Tissues were incubated with ${ }^{32} \mathrm{P}_{\mathrm{i}}$ for the times indicated as described in 'Methods'. Each point represents the mean for four determinations for the organ of Corti $(\bullet)$ and six determinations for the lateral wall tissues (stria vascularis and spiral ligament; $\mathbf{a}$ ). apical = filled symbols; basal $=$ open symbols 
apical lateral wall $(16550 \pm 5710 \mathrm{cpm} / \mu \mathrm{g}$ protein vs. $6120 \pm 1740 \mathrm{cpm} / \mu \mathrm{g}$ in the basal lateral wall; $P<0.05$, $N=6$ ). In addition, labeling in basal lateral wall was higher than its respective portion of the organ of Corti. Total ${ }^{32} \mathrm{P}$-phospholipids were $6890 \pm 1780 \mathrm{cpm} / \mu \mathrm{g}$ protein in the apical organ of Corti, while only 3420 $\pm 850 \mathrm{cpm} / \mu \mathrm{g}$ protein in the base (significant difference, $P<0.05, N=4$ ).

\section{Effect of exogenous substrates}

To test whether lipid labeling was influenced by the availability and differential distribution of phospholipid precursors, we examined the effect of exogenous substrates of phospholipid metabolism, inositol and choline ( $1 \mathrm{mM}$ each), on ${ }^{32} \mathrm{P}$-labeling in the base and apex of the cochlea. Cytidine (10 mM) was also added to the incubation medium since cytidine nucleotides are required for the incorporation of inositol or choline into phosphatidylinositol or phosphatidylcholine, respectively. The concentrations chosen were based on established $\mathrm{K}_{\mathrm{m}}$ values for the substrates in their respective synthetic pathways (Imai and Gershengorn, 1987; Ansell and Spanner, 1982; Carter and Kennedy, 1966).

The addition of the substrates increased the overall efficiency of phospholipid labeling but the base/apex differential remained. In lateral wall tissues, ${ }^{32} \mathrm{P}$-labeling of apical phospholipids was $35430 \pm 6020 \mathrm{cpm} / \mu \mathrm{g}$ protein after $90 \mathrm{~min}$ of incubation, versus $14550 \pm 3020$ $\mathrm{cpm} / \mu \mathrm{g}$ in the base (significant difference, $P<0.001$, $N=7$ ). Labeling of total phospholipids also remained higher in the apical organ of Corti $(7700 \pm 1640$ $\mathrm{cpm} / \mu \mathrm{g}$ protein), compared to the base $(3930 \pm 620$ $\mathrm{cpm} / \mu \mathrm{g}$ protein; $P<0.05, N=4$ ).

\section{Glucose-6-phosphate labeling}

Differences in the specific radioactivity of ATP between base and apex would create differences in base/apex phospholipid labeling. Therefore, the incorporation of ${ }^{32} \mathrm{P}_{i}$ into glucose-6-phosphate was examined as a measure of cochlear ATP mctabolism. In addition, the conversion of added 2-deoxyglucose to its 6-phosphate was determined. Unlike glucose-6-phosphate, 2-deoxyglucose-6-phosphate is not further metabolized and therefore not subject to possible base/apex differences in the glycolytic pathway. No significant difference was observed in the incorporation of ${ }^{32} \mathrm{P}_{\mathrm{i}}$ into glucose-6-phosphate from apical and basal cochlear tissues (Table I). Similarly, no difference was observed in the conversion of 2-deoxyglucose to 2-deoxyglucose-6-phosphate.

\footnotetext{
${ }^{32}$ P-labeling of individual phospholipids

${ }^{32} \mathrm{P}$ was incorporated into phosphatidate (Ptd), phosphatidylinositol (PtdIns), phosphatidylinositol phosphate (PtdInsP), phosphatidylinositol bisphosphate (PtdInsP $\left.\mathrm{P}_{2}\right)$, phosphatidylethanolamine (PtdEth),
}

TABLE I

PHOSPHORYLATION OF GLUCOSE-6-PHOSPHATE AND DEOXYGLUCOSE-6-PHOSPHATE

\begin{tabular}{lcl}
\hline & \multicolumn{2}{c}{$\mathrm{dmp} / \mu \mathrm{g}$ protein } \\
\cline { 2 - 3 } & apical & basal \\
\hline $\begin{array}{l}\text { Organ of Corti } \\
\text { 32 P-G6P }\end{array}$ & $3162 \pm 710$ & $2452 \pm 752$ \\
${ }^{3} \mathrm{H}-$ DG6P & $10500 \pm 1900$ & $8494 \pm 3415$ \\
Lateral wall & & \\
32P-G6P & $1770 \pm 540$ & $1827 \pm 720$ \\
${ }^{3}$ H-DG6P & $5090 \pm 1214$ & $4440 \pm 1440$ \\
\hline
\end{tabular}

Cochlear tissues were incubated with ${ }^{32} \mathrm{P}_{\mathrm{i}}$ and ${ }^{3} \mathrm{H}$-deoxyglucose as described in 'Methods', Values are means \pm S.D. $(N=8)$. There are no significant differences between base and apex ( $t$-test). Abbreviations: G6P - glucose-6-phosphate, DG6P - 2-deoxygucose-6-phosphate.

and phosphatidylcholine (PtdCho) in all cochlear tissues, and in both base and apex. Differences were found, however, in the relative abundance of cochlear phospholipids (defined as ${ }^{32} \mathrm{P}$-incorporation into an individual lipid / total ${ }^{32} \mathrm{P}$-incorporation) (Table II) such that each tissue exhibited a unique pattern of relative abundances of the labeled phospholipids.

After $90 \mathrm{~min}$ of incubation, PtdIns was the most abundant of the labeled phospholipids in all tissues except the basal lateral wall, where PtdIns and PtdCho were labeled to a similar extent. ${ }^{32} \mathrm{P}-\mathrm{PtdCh}$ exhibited the second-highest relative abundance in both the apical lateral wall and the basal organ of Corti, whereas in the apical organ of Corti, the relative abundance of PtdCho and PtdInsP $P_{2}$ were similar. In both lateral wall and organ of Corti, PtdInsP $P_{2}$ relative abundance was higher than PtdInsP. These two tissues differed in the

\section{TABLE II}

${ }^{32}$ P-LABELLING OF COCHLEAR PHOSPHOLIPIDS

\begin{tabular}{|c|c|c|c|c|}
\hline & \multicolumn{4}{|c|}{ relative abundance ( $\%$ of total) } \\
\hline & \multicolumn{2}{|c|}{ Lateral wall } & \multicolumn{2}{|c|}{ Organ of Corti } \\
\hline & apical & basal & apical & basal \\
\hline$\overline{\text { PtdInsP }} 2$ & $7.4 \pm 1.5$ & $11.7 \pm 3.2^{*}$ & $19.9 \pm 4.7$ & $14.3 \pm 1.8$ \\
\hline PtdInsP & $5.8 \pm 1.7$ & $6.6 \pm 1.0$ & $10.5 \pm 1.0$ & $7.5 \pm 0.1 *$ \\
\hline PtdIns & $41.6 \pm 6.5$ & $30.9 \pm 5.9 *$ & $35.2 \pm 2.5$ & $37.8 \pm 1.8$ \\
\hline PtdCho & $25.7+7.4$ & $33.6+3.1 *$ & $19.4+3.1$ & $26.7 \pm 1.8 *$ \\
\hline PtdEth & $2.9 \pm 1.2$ & $6.4 \pm 2.3 *$ & $3.3 \pm 0.3$ & $3.3 \pm 0.3$ \\
\hline Ptd & $16.5 \pm 2.9$ & $10.7 \pm 2.5 *$ & $8.2 \pm 0.4$ & $6.1 \pm 0.3 *$ \\
\hline
\end{tabular}

Isolated cochlear tissues were incubated in buffer containing 600 $\mu \mathrm{Ci}^{32} \mathrm{P}_{\mathrm{i}} / \mathrm{ml}$ with $1 \mathrm{mM}$ inositol, $1 \mathrm{mM}$ choline, and $10 \mathrm{mM}$ cytidine as described in 'Methods'. Results are expressed as means \pm S.D. ( $N=8$ for lateral wall tissues; $N=4$ for organ of Corti).

* Significant difference between apical and basal vaules $(P<0.05$; unpaired $t$-test). Abbreviations: Ptd $=$ phosphatidic acid; PtdIns $=$ phosphatidylinositol; PtdInsP $=$ phosphatidylinositol phosphate; PtdIns $P_{2}=$ phosphatidylinositol bisphosphate; PtdCho = phosphatidylcholine; PtdEth = phosphatidylethanolamine. 
fact that Ptd had a higher relative abundance than PtdInsP for the lateral wall, while the opposite was true for the organ of Corti.

A comparison of individual lipids in apex and base revealed additional differences between cochlear tissues. In lateral wall tissues, the relative abundances of PtdIns and Ptd were significantly higher in the apex, compared to the base. In the organ of Corti, PtdInsP was significantly higher in the apex. In addition, the relative abundance of $\mathrm{PtdCho}$ was higher in the base for both the lateral wall and the organ of Corti, whereas the relative abundance of $\mathrm{PtdIns}_{2}$ was higher only in the basal lateral wall, and not the basal organ of Corti.

\section{Phosphoinositide hydrolysis}

Total ${ }^{3} \mathrm{H}$-inositol phosphate accumulation was used as a measure of phosphoinositide hydrolysis. After 40 min of hydrolysis, ${ }^{3} \mathrm{H}$-inositol phosphates were 1.5 -fold higher in the apical organ of Corti, compared to the base $(480 \mathrm{dpm} / \mu \mathrm{g}$ protein vs. $325 \mathrm{dpm} / \mu \mathrm{g}$ in the base; significant difference, $P<0.02$, paired $t$-test, $N=5$ ).

\section{Discussion}

While previous studies have addressed phospholipid metabolism in the cochlea (Orsulakova et al., 1976; Ono and Schacht, 1989; Wang and Schacht, 1990), this is the first report of base/apex differences in phospholipid labeling. Our findings have important implications for the involvement of phospholipid-based second messenger systems in the physiology and pathology of the inner ear. Before these implications can be addressed, however, potential mechanisms for the base/apex differences in phospholipid metabolism need to be discussed. Mechanisms unrelated to the activation of second messenger systems could account for differences in phospholipid labeling.

First, differences in the specific radioactivity of $\left[{ }^{32} \mathrm{P}\right]$-ATP need to be ruled out. $\left[{ }^{32} \mathrm{P}\right]$-orthophosphate is incorporated into $\left[\gamma^{32} \mathrm{P}\right] \Lambda \mathrm{TP}$, the direct precursor of the labeled phospholipids. A higher specific activity of ATP in the apical cochlea would be reflected in increased labeling of apical phospholipids. However, ATP is also the precursor for the phosphorylation of other compounds, including glucose-6-phosphate, which did not exhibit higher labeling in the apex. In addition, no base/apex difference was observed in the conversion of 2-deoxyglucose to 2-deoxyglucose-6phosphate. These results are evidence that the observed phospholipid labeling patterns are based on differences in metabolism other than ATP specific activity. The relative abundance of the various phospholipids provides further evidence for this. In the case of an ATP gradient, all lipids would be equally affected, and no differences in relative abundance of the phospholipids should be observed.
Secondly, the gradient in phospholipid metabolism could be the result of differences in the availability or distribution of onc or more substrates of phosphoinositide or phosphatidylcholine synthesis. More specifically, a lack of substrates such as choline or inositol in the basal cochlea could result in lower phospholipid labeling. However, labeling in basal tissues was persistently lower, even with the addition of these precursors to the incubation medium. Furthermore, despite the lower total labeling, the relative abundance of both phosphatidylcholine and phosphatidylinositol bisphosphate was higher in the base. If substrate availability were a factor, the added substrates would equalize the relative abundance of phospholipids in base and apex. These results are evidence that substrate availability does not contribute to the differential distribution of cochlear phospholipid metabolism.

We are, then, left with differences in the distribution of metabolic enzymes as the mechanism for the results presented herein. We have preliminary evidence that diacylglycerol kinase exhibits higher activity in the apical cochlea (Niedzielski and Schacht, 1991), in correlation with the higher ${ }^{32} \mathrm{P}$-labeling. The product of the diacylglycerol kinase reaction is phosphatidic acid, which is a precursor for phosphoinositide synthesis. Additional evidence for differences in enzymatic distribution is provided by the inositol phosphate release experiments. The increased release of inositol phosphates in the apical organ of Corti should arise from an increased activity of the hydrolyzing enzyme, phospholipase $\mathrm{C}$. Thus, all results are compatible with the interpretation that the base/apex differences in cochlear phospholipid labeling are due to the differential distribution of rate-limiting enzymes.

The implications of our findings for inner ear physiology centers on the relative abundance of precursors of two lipid-derived second messenger systems. First, the relative abundance of phosphatidylcholine is higher in the basal portions of the cochlea. Phosphatidylcholine is now recognized as a precursor molecule for second messengers (Pelech and Vance, 1989), particularly diacylglycerol, similar to the well-established role of the phosphoinositides. The distribution of phosphatidylcholine parallels that of outer hair cell efferent innervation and may be associated with stimulated protein kinase $\mathrm{C}$ activity. In addition, the relative abundance of phosphatidylinositol bisphosphate is higher in the basal lateral wall tissues. This correlates with the increased $\mathrm{Na}^{+}-\mathrm{K}^{+}$ATPase activity in the basal stria vascularis (Kuijpers and Bonting, 1969) and is consistent with a role for the phosphoinositide second messenger cascade in the control of ion concentrations within the endolymph.

In contrast to the lateral wall tissues, the base/apex distribution of phosphoinositide labeling in the organ of Corti does not show obvious parallels with known 
gradients, including the distribution of cholinergic innervation at the outer hair cells. However, one of the limitations of these experiments is that a variety of cell types in the organ of Corti contribute to the results. Thus, the presence of the phosphoinositides in supporting cells may be masking the distribution of the phosphoinositides in the hair cells. Phospholipid labeling has been observed qualitatively in isolated outer hair cells (Williams et al., 1987), as well as supporting cells (unpublished observations). Furthermore, the present data demonstrate only that unstimulated metabolism of the phosphoinositides is higher in the apical cochlea. Hormone- or transmitter-stimulated breakdown of the phosphoinositides, on the other hand, is mediated by receptor activation and may show different distribution patterns. Stimulation of the phosphoinositide cascade via muscarinic receptors has been demonstrated by Guiramand et al. (1990) in the rat cochlea, and we have provided preliminary data that muscarinic receptor-stimulated phosphoinositide metabolism is higher in the basal organ of Corti of the mature guinea pig (Niedzielski and Schacht, 1991). By controlling the available precursor pool, differential stimulated and unstimulated phosphoinositide metabolism may provide a mechanism for temporal regulation of second messenger generation in the cochlea.

A more speculative role for base/apex differences in phospholipid metabolism involves cochlear pathology. Aminoglycoside toxicity may be influenced by the differential distribution of cochlear phospholipid metabolism. Our laboratory has previously demonstrated that neomycin binds to the phosphoinositides and inhibits their hydrolysis (Schacht, 1978; Schacht, 1976). If the phosphoinositides are essential for physiologic mechanisms then a disruption of lipid metabolism by the aminoglycosides will have a greater effect in the base due to the smaller second messenger precursor pool. This could result in the observed susceptibility of the basal organ of Corti to the aminoglycosides (Ylikoski, 1974; Hawkins et al., 1977).

In conclusion, the differential distribution of phospholipid metabolism has important implications for the regulation of second messenger precursor availability and for aminoglycoside toxicity. Similar findings for the distribution of other cochlear components suggest a functional differentiation between the base and apex of the cochlea. The integration of present and future information regarding distribution patterns within the cochlea will lead to a better understanding of auditory processing at the periphery.

\section{Acknowledgement}

This research was supported by NIH program project grant DC-00078 and training grant DC-00011.

\section{References}

Ahlström, P., Thalmann, I., Thalmann, R. and Ise, I. (1975) Cyclic AMP and adenylate cyclase in the inner ear. Laryngoscope 85 , 1241-1258.

Ansell, G.B. and Spanner, S. (1982) Phosphatidylserine, phosphatidylethanolamine and phosphatidylcholine. In: J.N. Hawthorne and G.B. Ansell (Eds.), Phospholipids, Elsevier Biomedical Press, Ansterdan, The Netherlands, pp. 1-49.

Axelrod, J., Burch, R.M. and Jelsema, C.L. (1988) Receptor-mediated activation of phospholipase $\mathrm{A} 2$ via GTP-binding proteins: arachidonic acid and its metabolites as second messengers. Trends Neurosci. 11, 117-123.

Bandurski, R.S. and Axelrod, B. (1951) The chromatographic identification of some biologically important phosphate esters. J. Biol. Chem. 193, 405-410.

Bradford, M.M. (1976) A rapid and sensitive method for the quantitation of microgram quantities of protein utilizing the principle of protein-dye binding. Anal. Biochem. 72, 248-254.

Carter, J.R. and Kennedy, E.P. (1966) Enzymatic synthesis of cytidine diphosphate diglyceride. J. Lipid Res. 7, 678-683.

Dean, N.M. and Beaven, M.A. (1989) Methods for the analysis of inositol phosphates. Anal. Biochem. 183, 199-209.

Eybalin, M., Parnaud, C., Geffard, M. and Pujol, R. (1988) Immunoelectron microscopy identifies several types of GABA-containing efferent synapses in the guinea-pig organ of Corti. Neuroscience 24, 29-38.

Fex, J., Altschuler, R.A., Kachar, B., Wenthold, R.J. and Zempel, J.M. (1986) GABA visualized by immunocytochemistry in the guinea pig cochlea in axons and endings of efferent neurons. Brain Res. 366, 106-117.

Godfrey, D.A. and Ross, C.D. (1985) Enzymes of acetylcholine metabolism in the rat cochlea. Ann. Oto. Rhino. Laryngol. 94, 409-414.

Guiramand, J., Mayat, E., Bartolami, S., Lenoir, M., Rumigny, J.-F., Pujol, R. and Recasens, M. (1990) A $\mathrm{M}_{3}$ muscarinic receptor coupled to inositol phosphate formation in the rat cochlea? Biochem. Pharmac. 39, 1913-1919.

Hawkins, J.E., Jr., Stebbins, W.C., Johnsson, L.-G., Moody, D.M. and Muraski, A. (1977) The patas monkey as a model for dihydrostreptomycin ototoxicity. Acta Otolaryngol. 86, 110-116.

Hallcher, L.M. and Sherman, W.R. (1980) The effects of lithium ion and other agents on the activity of myo-inositol-phosphatase from bovine brain. J. Biol. Chem. 255, 10896-10901.

Imai, A. and Gershengorn, M.C. (1987) Independent phosphatidylinositol synthesis in pituitary plasma membrane and endoplasmic reticulum. Nature 325, 726-728.

Kuijpcrs, W. and Bonting, S.L. (1969) Studies on ( $\mathrm{Na}^{+}-\mathrm{K}^{+}$)-activated ATPase XXIV. Localization and properties of ATPase in the inner ear of the guinea pig. Biochim. Biophys. Acta 173, 477-485.

Lisanti, M.P., Rodriguez-Boulan, E. and Saltiel, A.R. (1990) Emerging functional roles for the glycosyl-phosphatidylinositol membrane protein anchor. J. Mem. Biol. 117, 1-10.

Niedzielski, A. and Schacht, J. (1991) Phosphoinositide metabolism in the cochlea: distribution of enzymes and carbachol-stimulated turnover. Abstr. Assoc. Res. Otolarnygol. 14, 135.

Offner, F.F., Dallos, P. and Cheatham, M.A. (1987) Positive endocochlear potential: Mechanism of production by marginal cells of stria vascularis. Hear. Res. 29, 117-124.

Ono, T. and Schacht, J. (1989) Acoustic stimulation increases phosphoinositide breakdown in the guinea pig cochlea. Neurochem. Int. 14, 327-330.

Orsulakova, A., Stockhorst, E. and Schacht, J. (1976) Effect of neomycin on phosphoinositide labelling and calcium binding in guinea-pig inner ear tissues in vivo and in vitro. J. Neurochem. 26, 285-290.

Pelech, S.L. and Vance, D.E. (1989) Signal transduction via phosphatidylcholine cycles. Trends Biochem. Sci. 14, 28-30. 
Schacht, J. (1976) Inhibition by neomycin of polyphosphoinositide turnover in subcellular fractions of guinea pig cerebral cortex in ivtro. J. Neurochem. 27, 1119-1124.

Schacht, J. (1978) Purification of polyphosphoinositides by chromatography on immobilized neomycin. J. Lipid Res. 19, 106.31067 .

Schacht, J. (1985) Hormonal regulation of adenylate cyclase in the stria vascularis of the mouse. Hear. Res. 20, 9-13.

Schacht, J. and Zenner, H.-P. (1987) Evidence that phosphoinositides mediate motility in cochlear outer hair cells. Hear. Res. 31 . $155-160$.

Spoendlin, H. (1985) Anatomy of cochlear innervation. Am. J. Oto laryngol. 6, 453-467.

Sterkers, O. (1985) Origin and electrochemical composition of endolymph in the cochlea. In: D.G. Drescher (Ed.), Auditory Biochemistry, Charles C Thomas, Springfield, IL., pp. 473-487.
Van Rooijen, L.A.A., Seguin, E.B. and Agranoft, B.W. (1983) Phosphodiesteric breakdown of endogenous polyphosphoinositides in nerve ending membranes. Biochem. Biophys. Res. Comm. 112. $919-926$.

Wang, S. and Schacht, J. (1990) Insulin stimulates protein synthesis and phospholipid signaling systems but does not regulate glucose uptake in the inner ear. Hear. Res. 47, 53-62.

Williams, S.A., Zenner, H.-P., and Schacht, J. (1987) Three molecular steps of aminoglycoside ototoxicity demonstrated in outer hair cells. Hear. Res. 30, 11-18.

Ylikoski, J. (1974) Correlative studies on the cochlear patholngy and hearing loss in guinea pig after intoxication with ototoxic antibiotics. Acta Otolaryngol. Suppl, 326, 5-62. 